\title{
Valve-sparing aortic root replacement and the bicuspid aortic valve: The details matter
}

\author{
Leonard N. Girardi, MD
}

\author{
From the Department of Cardiothoracic Surgery, Weill Cornell Medicine, New York, NY. \\ Disclosures: Author has nothing to disclose with regard to commercial support. \\ Received for publication Dec 18, 2017; accepted for publication Dec 27, 2017; available ahead of print Jan 19 , \\ 2018. \\ Address for reprints: Leonard N. Girardi, MD, 525 East 68th St, M-404, New York, NY 10065 (E-mail: lngirard@ \\ med.cornell.edu). \\ J Thorac Cardiovasc Surg 2018;155:1412-3 \\ $0022-5223 / \$ 36.00$ \\ Copyright (c) 2018 by The American Association for Thoracic Surgery \\ https://doi.org/10.1016/j.jtcvs.2017.12.105
}

In this issue of the Journal, Klotz and colleagues ${ }^{1}$ report their experience with valve-sparing aortic root replacement (VSRR). They operated on 315 patients over a 20-year period (type A dissections were excluded) and reported near normal survival when comparing those having remodeling $(n=101)$ or reimplantation $(n=214)$ with equivalent members of an age- and gender-matched German population. The approximately 75\% 15-year survival for the overall cohort is admirable and comparable to that reported by David and colleagues ${ }^{2}$ (77.9\% 15-year survival) in a similarly sized cohort undergoing reimplantation VSRR over a similar period of time. The need for reoperation in the Klotz series was not significantly different at 10-year follow-up regardless of whether patients underwent remodeling or reimplantation $(5.8 \%$ vs $11.7 \%, P=.65)$. The presence of a bicuspid aortic valve (BAV) also was not predictive of the need for reoperation at 10 years (tricuspid aortic valve $9.8 \%$ vs BAV $5.3 \%, P=.13$ ). Given the concerns for long-term valve function after VSRR, it was disappointing to not see late echocardiographic data substantiating the durability of native valve function. Nonetheless, these results, combined with the excellent perioperative outcomes, lend additional support to VSRR as a viable option for a wide range of aortic root pathology.

However, the authors' central message highlights their concerns for a substantially increased need for reoperation in the second postoperative decade in patients receiving VSRR in the setting of a BAV. By using Landmark analysis, they reported a cumulative incidence of reoperation of $48.4 \%$ at 16 years, a disturbingly high need for reoperation that far exceeds any previously reported. ${ }^{3}$ The authors are to be commended for their thoughtful discussion on how to improve outcomes for patients with BAV in need of root replacement surgery. Ultimately, however, they suggest that perhaps one should take a closer look at a Bentall procedure as a more appropriate option in this setting. ${ }^{4}$ Is it appropriate to caution patients with BAV that the chances of reoperation at 15 years are approximately 50/50 (remember only 3 patients of 315 were 15 years out) or

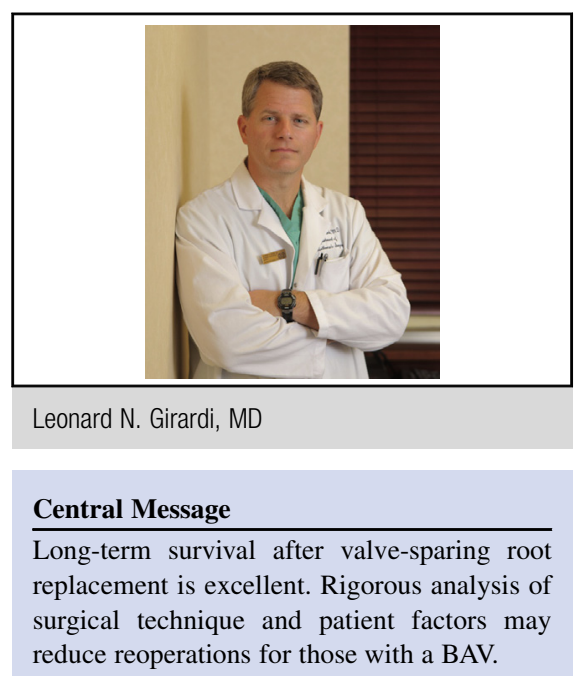

See Article page 1403

are there data telling us to delve into the nuances of this complex procedure and keep grinding it out?

In the largest series to date examining short- and longterm outcomes in patients with BAV undergoing VSRR, Schneider and colleagues ${ }^{3}$ reported a $21.7 \%$ cumulative incidence of reoperation at 15 years in 357 patients using a remodeling technique. Aortic regurgitation and stenosis both contributed to late valve failure. Furthermore, aortic valve calcification (hazard ratio, 4.34) and use of pericardial patch for partial cusp replacement (hazard ratio, 4.00) were identified as strong predictors of the need for reoperation on multiple regression analysis. These authors, like others, have taken a deep dive into VSRR for BAV and continue to modify their technique to improve results. Commissural orientation, ${ }^{5}$ effective leaflet height, ${ }^{6}$ the addition of an annuloplasty to remodeling techniques, and even the use of a graft with neosinuses rather than a straight one ${ }^{8}$ may all be important to further reduce the incidence of late valve failure and the need for reoperation. We owe it to our patients to continue this rigorous analysis and creative alteration of surgical technique to help patients avoid the long-term issues associated with valve replacement therapy.

\section{References}

1. Klotz S, Stock S, Sievers HH, Diwoky M, Petersen M, Stierle U, et al. Survival and reoperation pattern after 20 years of experience with aortic valve sparing root replacement in patients with tricuspid and bicuspid valves. J Thorac Cardiovasc Surg. 2018;155:1403-11.e1. 
2. David TE, David CM, Feindel CM, Manlhiot C. Reimplantation of the aortic valve at 20 years. J Thorac Cardiovasc Surg. 2017;153:232-8.

3. Schneider U, Feldner SK, Hofmann C, Schope J, Wagenpfeil S, Giebels C, et al. Two decades of experience with root remodeling and valve repair for bicuspid aortic valves. J Thorac Cardiovasc Surg. 2017; 153:S65-71.

4. Vallabhajosyula P, Szeto WY, Habertheuer A, Komlo C, Milewski RK, McCarthy F, et al. Bicuspid aortic insufficiency with aortic root aneurysm: root reimplantation versus Bentall root replacement. Ann Thorac Surg. 2016; 102:1221-8

5. Aicher D, Kumihara T, Abou Issa O, Brittner B, Graber S, Schafers HJ. Valve configuration determines long-term results after repair of the bicuspid aortic valve. Circulation. 2011;123:178-85.
6. Bierbach BO, Aicher D, Issa OA, Bomberf H, Graber S, Glombitza P, et al. Aortic root and cusp configuration determine aortic valve function. Eur J Cardiothorac Surg. 2010;38:400-6.

7. Lansac E, Di CI, Sleilaty G, Lejeune S, Berrebi A, Zacek P, et al. Remodeling root repair with an external aortic ring annuloplasty. J Thorac Cardiovasc Surg. 2017; 153:1033-42.

8. Oechtering TH, Frydrychowicz A, Sievers HH. Malrotated sinus vortices in straight graft valve-sparing aortic root treatment: a matter of concern? J Thorac Cardiovasc Surg. 2017;154:794-7.

9. Hammermeister K, Sethi GK, Henderson WG, Grover FL, Oprian C, Rahimtoola SH. Outcomes 15 years after valve replacement with a mechanical versus a bioprosthetic valve: final report of the Veterans Affairs randomized trial. J Am Coll Cardiol. 2000;36:1152-8. 